Wilfrid Laurier University

Scholars Commons @ Laurier

8-1-2019

\title{
From Inclusion to Inclusivity: A Scoping Review of Community Music Scholarship
}

Deanna Yerichuk

Wilfrid Laurier University, dyerichuk@wlu.ca

Justis Krar

Wilfrid Laurier University

Follow this and additional works at: https://scholars.wlu.ca/musi_faculty

Part of the Ethnic Studies Commons, and the Other Music Commons

\section{Recommended Citation}

Yerichuk, D. \& Krar, J. (2019). From inclusion to inclusivity: A scoping review of community music scholarship. International Journal of Community Music, 12(2), 169-188, doi: 10.1386/ijcm.12.2.169_1

This Article is brought to you for free and open access by the Faculty of Music at Scholars Commons @ Laurier. It has been accepted for inclusion in Music Faculty Publications by an authorized administrator of Scholars Commons@ @aurier. For more information, please contact scholarscommons@wlu.ca. 


\title{
From inclusion to inclusivity: A scoping review of community music scholarship Deanna Yerichuk and Justis Krar, Wilfrid Laurier University
}

\begin{abstract}
This article investigates how community music scholarship has taken up inclusion. Using a modified scoping review methodology, the authors analysed 47 articles published in the International Journal of Community Music from 2008 to 2018, examining how scholars have defined and operationalized the terms 'inclusion' and 'inclusivity', which were used interchangeably in the literature. The authors found that inclusion was often normatively invoked with no definition or approaches provided. In those articles that provided more detail about inclusion, many focused on musical access, such as removing auditions and not requiring previous music skill or knowledge, and processes of musical inclusion, such as creating a friendly and non-judgmental atmosphere, providing multiple ways of engaging with music-making and cultivating musical leadership among participants. Less frequent in the literature were ideas and approaches focusing on social inclusion through music, including frameworks that aimed to address and change systems that create marginalization; approaches that addressed social barriers to participation, such as transportation and childcare; and approaches that decentralized leadership to create collective responsibility and participation. The authors conclude by examining approaches from other scholarly disciplines, arguing that community music scholarship may benefit for more sustained and deliberate use of the term inclusivity, which points to the ongoing practice and effort towards inclusion.
\end{abstract}




\section{Keywords}

inclusion

inclusivity

community music

literature review

social inclusion

inclusive education

Many scholars assert that inclusion is a cornerstone of community music practice (Higgins and Willingham 2017), usually predicated on the widely circulating idea that everyone has a right to make music (Veblen and Olsson 2002), which we, the authors, also believe. However, despite a noticeable groundswell in using the terms 'inclusion' and 'inclusivity' in relation to community music over the last five years, there has been very little analysis of what these terms mean, nor how they are - or should be operationalized in community music settings.

This article represents our attempt to address the gap in the literature by first focusing on how community music scholars have been defining and using inclusion in research. The two of us began this research project when we realized that each of us had concerns about normative uses of inclusion in the Community Music scholarship that we were reading. Deanna had previously raised concerns about the normative uses of the term 'community' (Yerichuk 2014), in which the community is often already assumed and seen as always and only positive without much critical reflection of the social relations that constitute the social space, or the role of the facilitator in setting terms for 
participation in that community. Justis, through his course work, began to notice that the

term 'inclusion' seemed to be used in a passive sense in community music scholarship in which inclusion was described as a fait accompli rather than understood as an active continuing effort. However, with the growth of community music scholarship in the past five years, we both wanted to dig underneath our initial impressions and investigate just how inclusion has been written about and operationalized in community music scholarship. In collaboratively analysing community music scholarship, our hope is to identify how community music scholars have been defining and using the terms 'inclusion' and 'inclusivity', and in so doing, identify both gaps and possibilities for developing inclusion in theory and in practice within community music.

\section{Methods}

Our central concern focuses on how community music scholars have defined inclusion, and specific approaches that operationalized inclusion in community music. We therefore conducted a literature review based on scoping review methodology (Arksey and O'Malley 2005; Levac et al. 2010), which endeavours to map literature rapidly within a defined research area. Levac et al. (2010) describe five stages to scoping reviews that we briefly describe below, including the following: (1) defining the research question; (2) identifying relevant studies; (3) selecting studies to include; (4) charting the data; and (5) collating, summarizing and reporting. While we undertook all of these steps in our research, we narrowed our focus to look through ten years of issues published by the International Journal of Community Music, a more limited focus than most scoping reviews. However, given the specific focus of our question on the scholarly field of community music and the prominent role of the journal in publishing scholarship within 
the field, we felt that this delimitation would capture the largest number of diverse voices that had been vetted by global leaders in community music scholarship.

We approached the literature with two overarching questions: first, what exactly do community music scholars mean by inclusion? Second, what kinds of approaches to inclusion have been described in the literature? Within these questions are two terms to define. First, the term 'community music' is clearly the central organizing concept underpinning the entire research project. Defining community music is a well-trodden and contentious area that has been unpacked more thoroughly elsewhere (Higgins 2012; Veblen and Olsson 2002; Veblen 2008). Therefore, rather than defining community music, we chose to focus our research on literature published in the International Journal of Community Music under the assumption that articles published in the journal were deemed by journal editors to be community music. Second, the term 'inclusion' required some parameters to focus our project. Our central interest was in identifying how researchers have defined the term so we did not want to foreclose meanings; however, we determined that we were interested only in 'inclusion' insofar as the term applied to people, rather than applications to repertoire or music styles alone. We therefore broadly defined inclusion as a process related to people for the purpose of our study.

From these research questions we created a set of criteria to select studies for further analysis. Studies were included if they were published in the International Journal of Community Music and used the terms 'inclusion' or 'inclusivity'. Studies were excluded if the terms 'inclusion' or 'inclusivity' were either not used or were applied only to music repertoire or styles (e.g., one article focused on the inclusion of different forms of improvisation techniques, and so this article was excluded from our study). 
Once the criteria were established, we then reviewed the abstracts of all issues published between 2008 and 2018 to select articles according to these criteria. To chart the data, we created a form using Google Forms, which collected the following information: year of publication, title, author, definition of inclusion/inclusivity and approaches to inclusion/inclusivity. The researchers tested the form by extracting information from the same two articles to ensure that we were each locating the same information. Out of this test, we made minor adjustments to the form to reduce duplication in fields and ensure consistency in data extraction. The researchers then extracted data from the remaining articles.

We then analysed and summarized the extracted data using a specific sequence of analytical steps. Quantitative data were analysed using simple tables to identify trends (e.g, articles were tabulated by publication year). Qualitative data were analysed line by line within each form field using two cycles of coding in conjunction with two modes of analysis. The first coding cycle used in vivo coding or code that 'refers to a word or short phrase from the actual language found in the qualitative record' (Saldaña 2013: 91). In vivo coding enabled us to code using the specific terms, ideas and/or definitions of inclusion used by authors. Following the first round of coding, Deanna engaged in a code-mapping process, which organized in vivo codes into a preliminary set of categories. She then further condensed the categories into larger categories to create a preliminary analysis of key themes across the articles. Both researchers engaged in pattern coding as a second cycle of coding to reanalyse the first-cycle methods and conceptually organize the codes into themes (Saldaña 2013: 207). While the coding process allowed us to identify themes across the literature, we have endeavoured to 
adhere to Arksey and O'Malley's insistence that the purpose of a scoping study is 'to present a narrative account of existing literature', rather than assessing quality of evidence or search for generalizable findings (2005: 27).

Limits: While our literature review focused on research studies of community music, we are aware that the scholarship does not provide a complete picture of the kinds of practices that might be understood as inclusive. Very few of the articles took up inclusion as the main focus, which suggests that the articles likely do not capture all steps taken by community musicians to create inclusive music-making. However, we also recognize the ways in which published research begins to define the field of practice, and the very lack of sustained focus on inclusion as a concept, framework or deliberate set of strategies is precisely what drew each of us to carry out this research in the first place. In other words, while our research represents only a partial view of inclusive practices in community music, we hope that this first sustained focus on inclusion will set the groundwork to initiate necessary conversations that more fully and deeply grapple with what inclusive practice really means.

\section{Results}

Our dataset included a total of 47 articles published in the International Journal of Community Music from 2008 to 2018, all of which used the terms 'inclusion', 'inclusive' or 'inclusivity'. An analysis of articles by year showed a marked increase in the use of these terms in the last four years: more than three quarters (36 of 47 articles) were published between 2014 and 2018 .

Defining inclusion: Scholars in community music tended to use one of two terms: inclusion and inclusivity. There did not appear to be an analytical distinction 
between inclusion and inclusivity, and there was no clear reason given for choosing one term over the other. Further, a surprising number of articles used either of the terms normatively: we found that one-fifth of the articles (ten of 47 articles) used the terms 'inclusion', 'inclusivity' or 'inclusive' without providing any definition or framework. These articles seemed to understand inclusion normatively as either an aim or a result of the community music initiative. For example, Darby described an Arts Council mandate that 'everyone is entitled to participate in arts activities, including those in rural areas, because the arts make lifestyles and communities more enjoyable' (2015: 271). Baker et al. referred to the 'inclusive philosophy embedded in CoMT [Community Music Therapy]' (2017: 162) but do not define what they mean by this inclusive philosophy. Kruse described a ukulele club as demonstrating 'respect, acceptance, inclusiveness and wholeness' (2013: 158), which associates inclusion with other kinds of traits among the group without an explicit definition or focus on inclusion.

While a fifth of the articles did not explicitly define inclusion, the remaining 37 articles provided some definition, framework and/or strategies for inclusion. One-third of all articles (sixteen in total) described inclusion as a form of musical access. Many scholars argued that a basic tenet in community music is to welcome everyone irrespective of music skill or knowledge - what is sometimes called an 'open-door policy' (Balsnes 2016; Chadwick 2011) with no auditions. The rationale for music inclusion was most often linked to the idea that everyone deserves music (Veblen and Olsson 2002).

Only a small number of articles defined inclusion in more complex ways than open-door policies and participatory music-making. Notably, articles that focused on 
working with people with disabilities tended to write more about inclusion as a concept or how they operationalized inclusion through accommodations (Carpenter 2015; Reimann 2012; Smith 2013), perhaps not surprising, given that the very idea of inclusion emerged from special needs education in the 1970s (Berlach and Chambers 2011), an idea to which we return in the discussion. Boon described her work with disabled children in Turkey with her underlying belief system as 'everybody deserves the chance to interact musically through their body and psyche and to play alongside others in a group setting' (2015: 151-12). While this sounds similar to the 'everyone deserves to make music' philosophy prevalent in community music literature, Boon described the specific ways that she operationalized this belief, such as meeting with children and learning from them as individuals rather than as having "the same "disabled identity", (2015: 150). She also described how she collaborated with the children to explore both accommodations and creative possibilities, such as exploring wheelchairs creatively as a part of the dance rather than a limitation to dance.

Few other articles in our review defined inclusion or inclusivity explicitly, with two exceptions. In her article on a community chorus in Toronto, Yerichuk (2015) defined inclusion as the opportunity to participate and also as a response to injustice, drawing from Burnard et al. (2008). Phelan (2008) provided the most robust definition of inclusion by suggesting that community music operationalizes inclusivity through forms of music-making and through deliberate choices that affect participation related to social positions: 
In terms of community music, it is intriguing to think about how music-making can implicitly strategize behaviours such as inclusivity, accessibility or empowerment. Some forms of music-making may do this through repertoire, others through modes of performance (eg. improvisation), still others through participative choices related to gender, age, race or ability. (Phelan 2008: 148)

Phelan's definition of inclusivity focused on how facilitators can make deliberate choices that both conceptualize and musically enact values of inclusion.

Frameworks for inclusion: While not many scholars explicitly defined inclusion, many more scholars employed frameworks that related to inclusion, either implicitly or explicitly. Many scholars used Higgins' concept of hospitality to underpin how the facilitator adopts an inclusive stance for welcoming in participants (Balsnes 2016; Boon 2015; Howell 2013; Hill 2016; Sattler 2013; Snow 2013; Merwe 2017). Howell suggested that hospitality is built on creating 'space for the voices of others' (2013: 76) in which participants play active roles in determining the music-making. While Higgins' theory of hospitality was the most prevalent among CM scholarship, some scholars used other frameworks for the inclusive work of their community music projects, such as the United Nations Convention on the Rights of the Child (Brøske 2017; Niland 2017); culturally relevant pedagogy (Chadwick 2011); feminist poststructuralist framework (Bird 2017); and the ORIM framework (Niland 2017: 278), which stands for Opportunity, Recognition, Interaction and Modelling.

More articles also offered approaches and strategies for inclusive practices. Our analysis found that these approaches could be split into three general areas: musically 
inclusive practices; socially inclusive practices; and considerations of leadership and control. The following section details key ideas within each of these three areas.

Musically inclusive strategies: We looked for ways in which scholars operationalized inclusion through specific practices. Strategies and tactics to foster musical inclusivity were by far the most prevalent within the articles that we studied, which tended to be clear, concrete and relatively easy to implement.

No auditions: Auditions create perhaps the most common and obvious barrier to musical participation since they serve a gatekeeping function that exclude people from participating in music activities who may not have the skills, knowledge or 'talent' required by auditioned music groups. Clearly, if the goal of the musical activity is to enable anyone to participate, auditions run counter to inclusive music-making. Several authors described community music ensembles or activities that did not require participants to audition (Bird 2017; Carpenter 2015; Chadwick 2011; Kennedy 2009; Merwe 2017). Bird described a specific choir as non-auditioned to 'emphasize participation, inclusiveness and community building' (2017: 197). For initiatives aiming to be musically inclusive and participatory, removing auditions appears to be an excellent beginning to removing musical barriers to access. In contemporary (western) modernity, where music-making is often perceived as an activity only for professionally trained musicians, inclusive participation is predicated on removing the gate that might deny access to music-making.

No requirements of previous skill/experience: Related to removing auditions from music activities, several authors emphasized 'no experience necessary' as an important aspect of welcoming people into community music-making (Balsnes 2016; Garofolo 
2011; Garrett 2010). 'No experience necessary' was in part a stance that welcomed people who could not read music (Bird 2017; Carpenter 2015) and in part a statement of welcome for people who felt they were not skilled or talented at music-making (Kennedy 2009). Several authors wrote about the need for facilitators to communicate clearly and strongly with potential participants that they are welcome no matter how little experience they have or how bad they believe they sound. Kennedy described how a Canadian choir worked to welcome participants who want to sing and disregarded whether they can sing:

Those who had past negative experiences with singing would not have to fear another rejection. The registrar explained: 'We're a non-auditioned choir; the only criteria for being a member is you have to want to sing. And we don't really care if you think you can or not'. (2009: 188)

The registrar's comments above suggest that in addition to a policy of no experience required, musical inclusion may mean creating a friendly and musically non-judgmental space. Several other authors noted how successful musical experiences depend on the facilitator cultivating a positive attitude among participants, welcoming all irrespective of experience, and encouraging participants to develop at their own pace (Carpenter 2015; Chadwick 2011; Garofolo 2011; Kruse 2013). Garofolo (2011: 228) described a culture where mistakes are tolerated or even celebrated as a way of creating a musically nonjudgmental space.

Multiple ways of participating in music: A consequence to policies of welcoming participants irrespective of skill or experience is the need to provide multiple entry points 
to music-making. Often this was seen in purely musical terms, in which someone with basic skills could participate at a beginner level, and as their musicianship advances so too does the nature of their participation. For example, Garofolo described a marching band festival in the United States and how less experienced players began: 'If a person comes to us who can only play one note, we will assign him that one note. And at the point where he learns a second note we will assign him two notes' (2011: 229). Scholars emphasized that allowing participants to find their own way within the group enabled them to participate from where they are at musically, such as participating through dance and unpitched percussion (Merwe 2017); providing musical material in formats other than sheet music (Balsnes 2016; Carpenter 2015; Howell 2013); or participating in nonmusical roles, such as preparing refreshments (Hassan 2017).

Only a few scholars described how social relations shape people's comfort and ability to make music. In a study on South Africa's Field Band Foundation, van der Merwe (2017: 124) pointed out that female members often felt more comfortable dancing rather than learning an instrument, and so providing an opportunity for women just to dance was an important entry into the music-making. In thinking through how to be musically inclusive, van der Merwe's analysis of gender opened up considerations of the ways in which not only gender but also race, class, sexual orientation and physical ability can shape how people perceive their own or others' musical skills and capabilities.

Flexible structures to engage in music: Beyond strategies to increase access to community music (as in, creating ways to 'open the door' and keep the door open), some researchers described strategies and structures in music-making that contributed to inclusion. Some articles pointed to the ways in which the structure of the music-making 
affected the inclusivity of the event. For example, in her work with refugee children, Howell (2013) described how she created a flexible environment in which the young participants could come and go as they chose; they were not required to participate for the entire session nor for a period of time. In the Gettin' Higher Choir researched by Kennedy (2009: 189), participants could choose how many rehearsals to attend and also choose whether they participated in performances. Hassan (2017) described how the ReVoice Choir in England had an open membership in which participants could come and go. A choir for newcomers in Norway was so loosely structured that practices rarely started or finished on time, and ' $[\mathrm{t}]$ here was no form or registration or membership list, which meant that people came and went' (Balsnes 2016: 173).

Music repertoire: Musically inclusive strategies sometimes focused on the specific kinds of music being made, particularly in the context of the specific participants. One strategy from Balsnes (2016) was to choose or create music that represented the newcomers in the choir, such as creating new compositions based on stories of immigration, or singing songs commonly known among the participants. Another strategy was to mandate a culturally diverse repertoire that was not necessarily representative of the participants themselves but would introduce participants to a broad range of sounds, languages and cultures, such as a community choir in Toronto described by Yerichuk that had a mandate to sing songs 'in languages other than English, and... drawn from many world cultures' (2015: 219).

Processes of music-making: Some authors described specific strategies to encourage more inclusive music-making in which transmission processes focused on creating music. Several authors described improvisatory processes for music creation 
(Boon 2015; Mastnak and Neuwirthová 2017; Snake-Beings 2017). Boon, for example, described a process of dance creation with students of different physical abilities: 'we would undertake the creative process together by emphasizing openness to unpredictable musical outcomes and the collaborative invention of new music and choreography' (2015: 156). For activities using sheet music rather than improvisatory or collaborative creation processes, participants were often given alternative ways of learning the material such as lyrics sheets, rote learning or using audio recordings (Balsnes 2016: 184; Carpenter 2015: 204-05).

Overall, the musically inclusive practices that were described in the literature were concrete and relatively easy to implement, and often depended on the particular context of music-making. Several strategies contributed towards enriching participant experience, such as removing auditions, creating multiple pathways to participation, developing inclusive processes of music-making and diversifying repertoire. However, music inclusivity is only part of the equation. A very small number of the articles that we reviewed also considered socially inclusive approaches within community music.

Strategies for social inclusion: Most articles understood inclusion primarily in musical terms. Although some of the musical strategies described so far also suggest social considerations (such as encouraging participation through making refreshments or allowing participants to engage as they feel comfortable), most authors tended to frame inclusion as primarily musical, with social purposes for these musical choices remaining latent rather than explicitly named. However, a few scholars did explicitly focus on reducing social barriers in the structures and processes of participatory music-making, opening up possibilities for more robust understandings of inclusion in community music. 
What follows in this section could be seen as a kind of progression from simply recognizing the social systems affecting participation, to more complex strategies that attempt to address social barriers, and finally to initiatives that aimed to use musical processes to shift the social conditions that create inequities in the first place.

Recognizing social systems affecting musical participation: A few scholars emphasized the importance of recognizing the social conditions that create barriers to participation. These authors recognized the kinds of oppression people experience that structure the ways in which they can or will participate in any given music activity, such as 'age, gender, ethnicity, sexual identity, geographic location and health' (McFerran and Rickson 2014: 79). While this is similar to van der Merwe's (2017) musical strategies that acknowledged how gender shaped girls' participation in South Africa, a few scholars offered an even deeper analysis that more explicitly focused on the ways in which the social contexts of people's daily lives significantly affected whether they could participate in music-making at all. For example, Oehrle described another South African project in which the complex history and contemporary context affected whether youth would participate in that music programme, such as the 'separate and unequal education system' (2010: 381) created by decades of Apartheid; the AIDS crisis; and 'the breakdown of family and tribal values creates a sense of uprootedness, which is the result of the general economic, political, social and cultural changes during the last 60 years in South Africa’ (Oehrle 2010: 382).

Niland made this shift from individual to system most clearly in the context of working with people with disabilities. She employed a social model of disability in which 'disability does not exist solely within individuals but arises from social attitudes, 
environments and policies that create barriers to participation that may impact on identity, self-esteem and sense of belonging for people who experience disability' (2017: 276). Similarly, Boon demonstrated within her musical activity how the environment creates disability issues rather than bodies:

For a woman using a wheelchair, it is not her body or the wheelchair, but the stairs that disable her. The barriers of inaccessible architecture, historically shaped attitudinal barriers to disabled people, and the resulting institutional discrimination are now the disabling factors, not the individual body of a person. Within these terms, disability becomes a social and environmental issue, not a medical one. The social model of disability helped me construct barrier-free music workshops. (2015: 154-55)

Niland and Boon both emphasized an important shift in perspective on community music activities away from 'fixing' the marginalized individual and towards recognizing how systems marginalize people in the first place.

Reducing social barriers to participation: A few scholars wrote about specific approaches and challenges to reducing social barriers to participation. Perhaps the most prevalent policy among articles was to reduce financial barriers to participation. Many articles that we reviewed focused on reducing or eliminating fees to encourage participation (Bird 2017; Kennedy 2009; Rønningen 2017; Yerichuk 2015). Bird (2017) suggested an unusual format of asking members who can afford to pay more to support those members who cannot afford the amount. 
Beyond financial considerations, a few articles focused on community music activities that had policies designed to increase access by people marginalized by a number of circumstances. One author described how a Toronto choir ensured that rehearsals took place in fully accessible locations and at times that respected multi-faith calendars (Yerichuk 2015: 219). In another choral example, Carpenter (2015) described a choir of people with differing abilities in which the director instituted structures to reduce barriers to participation, such as developing a buddy system and creating multiple ways to practice outside of rehearsals. Carpenter considered these less as adaptations or accommodations and more as universal design that was 'of equal value to the music historian singing a part for the first time and to the young man with autism' (2015: 206). Childcare provision was noted in a few articles to enable parents to participate - women in particular (Phelan 2008; Yerichuk 2015). Time commitment was also flagged as a barrier. Barnes (2013) and Oehrle (2010) both noted that the time commitment for each of their projects could dissuade 'families who may have financial and time impediments' (Barnes 2013: 27).

Reducing physical barriers was highlighted by scholars who focused on people with disabilities, although noticeably absent in community music projects that did not specifically work with people with disabilities. Niland described the connection between physical barriers and children's rights to cultural participation: 'Physical environments may be inaccessible for mobility or sensory reasons, or the [music] programme may have normative expectations of children's behaviour and performance, [which] presents a barrier to the rights of children to engage in their musical cultures' (2017: 275). Transportation was listed as another key barrier for people with physical disabilities. 
Strategies to address transportation barriers included a text message process for people needing or offering rides (Balsnes 2016); setting up ride shares between disabled participants and participants who could drive (Carpenter 2015); and locating the music activities in close proximity of those who have issues with transportation (Barnes 2013).

Social barriers also varied according to the groups of participants. For choirs that welcome newcomers, several authors described techniques to reduce language barriers, such as using simple language and singing in many languages so that everyone has experience of singing in an unknown language (Balsnes 2016).

Creating socially safe spaces for participation: Creating a safe space could be understood as a more intensive analysis of how to reduce/remove barriers for participation. While many authors considered how to make a space musically safe or helping people overcome their fear of being judged for sounding bad, only a few scholars focused on social conditions that shape experiences of safety, such as recognizing that certain groups of people have been marginalized in ways that threaten personal security, such as women fleeing from violence or people experiencing homelessness. Goodrich wrote about an orchestra that gave concert tickets to 'battered women and homeless people' (2013: 53), but few showed up because the women's confidentiality would be compromised by attending and those living in the homeless shelter could not attend because the shelter closed before the end of the concert.

These two examples suggest that creating a safe space can be literally about ensuring that participants are not asked to compromise their physical comfort or safety. However, creating a safe space may also be about psychological or emotional safety. Some authors highlighted how power relations create specific vulnerabilities among some 
participants related to race, class, gender, ethnicity, ability and gender identity, among other subjectivities (Oehrle 2010; Yerichuk 2015). Acknowledging and reducing power differences seemed particularly important for facilitators who did not share the same vulnerabilities as the participants with whom they work. Boeskov noted that involving marginalized groups can 'contain feelings of sorrow, sadness, ambivalence or even anger [...] such practices comes with a heavy ethical responsibility of dealing with these feelings in appropriate ways' (2017: 96). These scholars emphasized the importance placed with the facilitator to recognize the vulnerabilities of participants without making assumptions. When facilitators work with vulnerable populations, those participants should be able to express themselves in a safe environment (Weston and Lenette 2016: $125)$.

Addressing systems of oppression through community music: Several scholars focused on music activities that aimed to address, challenge and/or change unjust systems through community music. In our review of articles, we found a few examples that seem to shift the focus from fixing the individual towards working collectively through music to change systems of domination. Notably, many of these projects tended to focus on groups of people with shared identities. Bird, for example, described a mixed-voice LGBTQI choir that not only gave 'space for the retention and performance of LGBTQI identities' but also ‘act[ed] as a political and educative voice for LGBTQI-identified people' (2017: 194). Boeskov wrote about a music activity for Palestinians in Lebanon that intended to create positive ideas of Palestine with the explicit intent that "performing this music is conceived to be acts of resistance towards the unjust social and political structures that determine the lives of the Palestinians in Lebanon' (2017: 94). Several 
authors focused on community music activities specific to a group that shared a common identity to strengthen that identity, whether racialized participants (Chadwick 2011; Li and Southcott 2012), LGBTQ+ (Bird 2017; Snow 2013) or shared musical-cultural identity (Snell 2014).

Another small set of articles focused on community music activities that engage in intercultural work. In describing the South African context, van der Merwe (2017) pointed out that engaging in cultural diversity could easily become a depolitical exercise of multiculturalism, and argued that:

[t]he choice of medium (the marching band) reflects both South Africa's colonial past and the hope for a decolonized community music practice. The diversity of musics incorporated in the [Field Band Foundation] repertoire, the reinterpretation of western popular music to include South African urban grooves, and the reinterpretation of the marching band to include distinctly South African dance styles, all speak to a genuine struggle to express the rich cultural diversity of the participants and to understand diversity as more than a theoretical exercise.

(Merwe 2017: 125)

By acknowledging the complex socio-historical context of the community music, in this case the marching band, van der Merwe pointed to the complexity of political work with the system that it tries to dismantle. In short, this perspective demonstrated the difficulty of shifting social relations through music while also pointing to its necessity. 
Writing from a very different context, Balandina reflected on a project that used music as a kind of intercultural work between Serbian and Croatian youth, arguing that 'intercultural musicking constructs new possibilities for cross-cultural understanding and may provide a paradigm for peaceful coexistence among the various ethnic groups in one nation-state' (2010: 230). While the context and programme are quite different to van der Merwe, both authors wrote about the role of music in culture, where music is a vehicle through which histories and contemporary realities are addressed and shifted. The connection of community, song, place and cultures, particularly in the context of colonization, opens up a distinct and necessary line of thinking and questioning around inclusion in community music - who is including whom with what music and to what ends? Issues of music in relation to indigeneity open up important questions about the entire model of inclusion within community music, in which the project of inclusion may shift or become less relevant from perspectives of decolonization or reconciliation.

Considerations of leadership and control: Most articles focused on community music activities in which a facilitator led the group music activity. If there is a facilitator who leads the participatory music-making, this facilitator likely holds significant responsibility in creating inclusive music-making environments. While no authors explicitly addressed the question of how much control the facilitator could or should have in setting conditions for participation, many authors described forms of leadership that suggest that there are multiple ways for facilitators to think through their relationship to the group and how decisions get made in relation to creating inclusive music-making. In some articles, facilitators held decision-making power and tended to set the terms for participation. Often choral conductors or band directors exhibited this more centralized 
leadership role (Bird 2017; Carpenter 2015; Chadwick 2011; Garofolo 2011; Yerichuk 2015), although some research on choirs focused on ways in which the participants also guided the social and musical development of the group (Balsnes 2016; Hassan 2017; Yerichuk 2015). Other examples described the facilitator role as less of a leader and more of a convener who gathers a group of people to create without providing strong or direct guidance (Howell 2013; Phelan 2008). In our review, Bartleet (2009) stood out as the only author who inverted the relationship between facilitator and participants by suggesting that ownership of the musical process should belong to the people engaging in the music.

Many articles focused on collaborative models of leadership, with a clear facilitator who used strategies that encouraged participants to take on active roles in the music-making processes. For example, several authors spoke to the importance of forming relationships with participants to develop a sense of trust and comfort (Niland 2017: 279) but also to help craft music activities tailored to the experiences, challenges and possibilities of the specific group. This was most prevalent in articles focusing on populations with neuro diversities or differing abilities that the facilitator did not share. Boon, for example, wrote about working with a group of children with disabilities 'as unique individuals each with different capacities' (2015: 150), emphasizing the importance of understanding how each participant can contribute their unique voice to the music rather than the facilitator assuming what a person or a group can or cannot accomplish.

Another strategy in sharing decision-making between facilitator and participants was to encourage participants to provide feedback or collaborate in designing the musical 
process, which 'enables and empowers people to use their skills effectively' (McFerran and Rickson 2014: 85). The authors described this collaborative approach in various facilitation contexts, including working with children (Boon 2015), families (Niland 2017), newcomers (Balsnes 2016) and youth (Balandina 2010). The authors argued that facilitators should collaborate with participants to increase participation in the music activity (Garrett 2010) or that collaborations would create space for participants to take initiative to develop their own inclusive practices (Smith 2013) and policies (Yerichuk 2015) to support the musical and social experiences of the group.

Many of the articles that we examined paid very careful attention to the participants, and several authors described various techniques that facilitators used to get to know their participants and build relationships before and during music activities. However, not one article in our review suggested that facilitators should also examine themselves in relation to their participants. The closest that any author came to identifying how facilitators could or should be aware of their own positionalities were articles that included a description of facilitators who shared similar backgrounds to participants. In particular, a few authors focused on facilitators with an immigrant or cultural background being effective in reaching out to groups with similar backgrounds (Balandina 2010; Balsnes 2016; Daria 2018). Some authors addressed critical questions about the relationship between facilitator and participants within articles where differences between facilitator and participants were most obvious, such as facilitators without disabilities working with people with disabilities (Boon 2015; Carpenter 2015) and non-minorityidentified facilitators working with people from minority cultures, such as newcomers (Balandina 2010; Balsnes 2016). For example, Balsnes (2016) described a refugee choir 
in Norway that encouraged refugee participants to talk in their own languages so that Norwegian singers were in fact at a disadvantage. This, argued Balsnes, levelled the power relations so that refugees, so often at a linguistic disadvantage in their lives, now had a space in which their own languages were dominant: ' $[t]$ his could exclude the Norwegian participants from the conversation; however, in this context it rather contributed to levelling of power' (2016: 183).

Overall, questions of leadership and control were not central in scholarship related to inclusion, but a few articles opened up important questions about the relationship between participants and facilitator.

\section{Discussion}

Based on our review of articles published in the International Journal of Community Music from 2008 to 2018, inclusion has become increasingly important to scholars over the past four years in particular. While our qualitative analysis cannot definitively account for this recent increase in the use of the term, we note that the rise in usage occurred after the publication of Lee Higgins' influential book Community Music: In Theory and Practice (2012). Higgins did not focus directly on inclusion in the book, and yet his concepts of hospitality and the welcome informed how authors have approached inclusion in several of the articles within our scoping review. In the more recent publication of the textbook Engaging in Community Music: An Introduction (Higgins and Willingham 2017), the authors explicitly embed inclusivity within their very definition of community music, suggesting that the terms 'inclusion' and 'inclusivity' will continue to be prevalent within community music scholarship. 
Several articles within our analysis offered approaches that could inform inclusive practice. Very few articles, however, provided any sustained discussion or analysis of the very idea of inclusion/inclusivity. In those articles that provided more explicit focus on inclusion, the authors tended to focus on music-based strategies for inclusion, such as removing auditions, creating a friendly and non-judgmental atmosphere, providing multiple ways of engaging with music-making and cultivating musical leadership among participants. Less frequent in the literature were ideas and approaches that explicitly highlighted social aspects to inclusion, and yet the literature that did focus on social aspects of inclusion pointed to a more detailed and nuanced understanding of inclusion in theory and in practice. A small number of articles focused on frameworks that aimed to address and change systems that create marginalization, approaches that recognized social barriers to participation, such as transportation and childcare, and approaches that decentralized leadership to create collective responsibility and participation.

A need for frameworks focusing on social and musical inclusion: We identified a tendency within the literature to approach inclusivity primarily through a musical focus. That is, concerns about inclusivity tended to focus more on removing auditions and/or creating a welcoming atmosphere so that participants with less music experience feel encouraged to participate. Of course, all music-making is inherently social (Bowman 2009), but only a few scholars explicitly identified the ways in which social relations construct the music-making environment or acknowledged that inclusion efforts may need to grapple specifically with social relationships. There were a few scholars who focused on how the specific sociocultural contexts of the music-making activities affected participation. These kinds of analyses offer deeper perspectives on inclusive 
music practices by linking social conditions that differently structure people's abilities to participate. Further scholarship is needed to provide more robust analyses of systemic oppression in relation to community music and not just how community music responds to oppression but how social systems structure conditions of participation in music activities.

Critical questions of leadership and control: Almost all articles in our review assumed a model of community music described by Lee Higgins as an 'active intervention between a music leader or facilitator and participants' (Higgins 2012: 3). Consequently, articles foregrounded the role of the facilitator in music-making, with very few authors suggesting, like Bartleet (2009), that music practices might already circulate in some communities or that communities/participants may in fact own or control any music-making processes. Instead, most authors framed the facilitator as the host who invites participants into the music-making. Our review found very little focus on the positionality of the facilitator in relation to the participants, which suggests that community music scholarship has yet to grapple with the power dynamics between facilitator and participants. There is significant and urgent need for scholarly analysis that considers the dynamics between facilitator and participants not just musically, but socially, such as analysing intersections of race, class, gender and other intersecting subjectivities. Furthermore, sustained focus on leadership and control may elucidate the relationship between facilitator and participants to identify which models of leadership work in which contexts to produce more inclusive practices.

Drawing from other scholarly fields: Another noticeable gap in the research is articles that take up critical frameworks to determine how particular groups of people 
become marginalized and what groups of people benefit from the marginalization of others. Very few articles drew from critical frameworks that have been developed and/or refined in other disciplines, but a few articles did connect to other scholarly fields using feminist frameworks, critical pedagogy, disability activism, anti-racist frameworks, queer theory and/or intersectional analyses. The field of community music might look at these examples and draw connections between music, inclusivity and social justice through these critical frameworks that could incorporate an analysis of power within community music activities and offer particular strategies that might address systems of oppression through music.

Community music scholars have for the most part addressed the idea of inclusion in isolation from these other disciplines, and yet scholars outside of community music have developed robust theories and frameworks for inclusion that could deepen community music practice and research. In particular, community music may benefit from dialoguing with scholarship in the field of inclusive education, which emerged in the 1970s to focus on integrating children with special needs into school classrooms. This robust body of scholarship can inform community music as an inclusive practice in important ways, as demonstrated by the few CM scholars working musically with people with disabilities. Beyond the frameworks already mentioned in this article, there are many scholars in inclusive education who have written extensively about the power relationship between subjects of special education research and the non-disabled researchers (Allan 2007; Allan and Slee 2008; Slee 2001; Slee and Allan 2001), which parallels questions of leadership and control among CM facilitators and their participants. Inclusive education scholars have pointed out how policies aiming to accomplish 
inclusion may in fact miss engaging in critical reflection and constant learning when it comes to what inclusion really looks like (Allan 2007; Baglieri and Shapiro 2017; Slee 2001; Slee and Allan 2001; Titchkosky 2011). Similarly, CM scholarship may not focus enough on the importance of critical reflection for facilitators to fully grapple with the ways in which participants may be excluded despite good intentions.

At the same time, inclusive education researchers emphasize that inclusive education is about all students and not only about addressing specific disabilities only (Allan 2007; Baglieri 2012; Popkewitz 1998; Slee 2001; Slee and Allan 2001). In particular, Allan (2007), Popkewitz (2008), Titchkosky (2011) and Tomlinson (2017) emphasize how social exclusion and inequality create unjust systems that lead to exclusions in the first place, arguing that inclusive education 'asks direct questions: Who's in? and Who's out? The answers and their sharpest definition along lines of class, 'race', ethnicity and language, disability, gender and sexuality and geographic location' (Slee 2001: 116). Clearly, scholarship in inclusive education has developed robust frameworks and critiques that can significantly inform inclusive work in community music.

Inclusion versus inclusivity: Our analysis found no discernible difference between inclusion and inclusivity, suggesting that community music scholars have not considered whether these terms are merely derivatives of each other or point to different conceptual approaches to inclusive practice. CM scholarship could develop more robust inclusive models by drawing from inclusive education scholarship, which has differentiated inclusion and inclusivity. Forlin (2004) argues that inclusion refers to simply integrating children with special needs into classrooms, whereas inclusivity focuses on active 
teaching processes that provide optimal learning for all students (Forlin 2004: 196).

Similarly, Berlach and Chambers define inclusivity in a classroom context as 'embrac[ing] the challenge of providing the best possible learning environment for all children' (2011: 530, italics theirs). Both definitions frame inclusivity as active and ongoing, and inclusion as passive and complete. Community music scholars may consider making a similar distinction between inclusion as simply incorporation of nondominant groups and inclusivity as sustained effort to increase participation by nondominant groups. We encourage the field to consider a more deliberate use of the term 'inclusivity' to point to the ongoing commitment to the practice of inclusive community music, following Berlach and Chambers, who argue that inclusive practice is 'a mindset or a worldview that permits inclusivity to be realised' (2011: 531).

Questioning inclusivity: Finally, a question underneath all of these considerations around inclusion is as follows: is inclusivity always the frame to use, particularly if community music is concerned with 'engaging in social justice, political activism' (Higgins and Willingham 2017: 1)? This question came up for both authors as we engaged in our research project centred on inclusivity. We began to realize that the very idea of inclusivity hinges on a power differential that always locates the facilitator in the centre and participants on the outside. There may be a need to investigate models and approaches that do not use the terms 'inclusion' or 'inclusivity', but provide ways of thinking through the constitution of complex socio-musical spaces in communityoriented music-making. We note in particular two emerging bodies of literature that may open up alternatives to inclusion: scholarship related to music in the justice system (Cohen 2010) and scholarship within postcolonial contexts that considers intersections of 
music and indigenous communities within relationship to history and land (Bartleet and Carfoot 2016; Rickwood 2014; Vaugeois 2013).

Overall, the idea of inclusion seems to be an increasingly prevalent term organizing how the scholarly field of community music understands the practice. If the scholarly field is increasingly committed to the idea and practice of inclusion, there does appear to be a need to think not only about how to include but also how practices may in fact exclude. As Juliet Hess has argued, 'to include there must always be an outside, the excluded. [...] As we talk about inclusivity, we might ask ourselves whether we (we?) mean to include in a manner that is meaningful or intend to merely tolerate' (2018). As a part of this concern, we note that questions of inclusivity are more thoroughly answered through focusing not just on who is participating but also who is not participating, either by choice or by exclusion. Inclusivity is an active process that 'is not simply a matter of granting access, but about reaching out to those not attending' (Rønningen 2017: 36).

\section{Conclusion}

What is clear from our review is that inclusive community music practice is complex. By undertaking a review of inclusivity in community music scholarship, our hope is to identify gaps in research and also find possible paths forward to develop more robust ways of developing inclusive practices that are active and ongoing to address not

just musical barriers but social barriers as well. A very first step is to encourage the field to adopt the term 'inclusivity' to signal the deliberate, active, ongoing process necessary for inclusive community music. The time has come to think through inclusive practices more deeply in research than the participatory ethos that has undergirded the scholarly field to date. While it is clear that inclusive practices are complex, and rife with tensions 
and challenges that may never fully resolve, we believe that the development, examination and application of appropriate and context-specific frameworks will help scholars and practitioners deepen community music practice to serve more diverse groups of people in more meaningful ways.

\section{References}

Allan, J. (2007), Rethinking Inclusive Education: The Philosophers of Difference in Practice, Dordrecht: Springer Science \& Business Media.

Allan, J. and Slee, R. (2008), Doing Inclusive Education Research, Rotterdam: Sense Publishers.

Arksey, H. and O’Malley, L. (2005), 'Scoping studies: Towards a methodological framework', International Journal of Social Research Methodology, 8:1, pp. 1932.

Baglieri, S. and Shapiro, A. (2017), Disability Studies and the Inclusive Classroom: Critical Practices Embracing Diversity in Education, $2^{\text {nd }}$ ed, New York: Routledge.

Baker, F., Jeanneret, N. and Kelaher, M. (2017), 'Musomagic: Artist-led personal development programmes for youth as viewed through a Community Music Therapy lens', International Journal of Community Music, 10:2, pp. 157-69.

Balandina, A. (2010), 'Music and conflict transformation in the post-Yugoslav era: Empowering youth to develop harmonic inter-ethnic relationships in Kumanovo, Macedonia', International Journal of Community Music, 3:2, pp. 229-44. 
Balsnes, A. H. (2016), 'Hospitality in multicultural choral singing', International Journal of Community Music, 9:2, pp. 171-89.

Barnes, G. V. (2013), 'The University of South Carolina String Project: Teaching and learning within a community music programme', International Journal of Community Music, 6:1, pp. 23-31.

Bartleet, B.-L. (2009), 'Sound links: Exploring the social, cultural and educational dynamics of musical communities in Australia', International Journal of Community Music, 1:3, pp. 335-56.

Bartleet, B.-L. and Carfoot, G. (2016), 'Arts-based service learning with Indigenous communities: Engendering artistic citizenship', in D. Elliott, M. Silverman and W. Bowman (eds), Artistic Citizenship: Artistry, Social Responsibility, and Ethical Praxis, New York, NY: Oxford University Press, pp. 339-58.

Berlach, R. G. and Chambers, D. J. (2011), 'Interpreting inclusivity: An endeavour of great proportions', International Journal of Inclusive Education, 15:5, pp. 52939.

Bird, F. (2017), 'Singing out: The function and benefits of an LGBTQI community choir in New Zealand in the 2010s', International Journal of Community Music, 10:2, pp. 193-206.

Boeskov, K. (2017), 'The community music practice as cultural performance: Foundations for a community music theory of social transformation', International Journal of Community Music, 10:1, pp. 85-99. 
Boon, E. T. (2015), 'Everybody is a musician, everybody is an orchestra: Musical and bodily dialogues with physically disabled children in Turkey', International Journal of Community Music, 8:2, pp. 149-61.

Bowman, W. (2009), 'The community in music', International Journal of Community Music, 2:2, pp. 109-28.

Brøske, B. A. (2017), 'The Norwegian Academy of Music and the Lebanon Project: The challenges of establishing a community music project when working with Palestinian refugees in South Lebanon', International Journal of Community Music, 10:1, pp. 71-83.

Burnard, P., Dillon, S., Rusinek, G. and Saether, E. (2008), 'Inclusive pedagogies in music education: A comparative study of music teachers' perspectives from four countries', International Journal of Music Education, 26:2, pp. 109-26.

Carpenter, S. (2015), 'A philosophical and practical approach to an inclusive community chorus', International Journal of Community Music, 8:2, pp. 197-210.

Chadwick, S. (2011), 'Lift every voice and sing: Constructing community through culturally relevant pedagogy in the University of Illinois Black Chorus', International Journal of Community Music, 4:2, pp. 147-62.

Cohen, M. L. (2010), 'Editorial', International Journal of Community Music, 3:1, 1 March, pp. 3-6.

Darby, S. (2015), 'The impacts of a community orchestra in a rural setting: An insight into Borderland Community Orchestra', International Journal of Community Music, 8:3, pp. 259-78. 
Daria, J. (2018), 'Community music on campus: Collaborative research, activist methods and critical pedagogy in a fandango-based participatory music programme', International Journal of Community Music, 11:1, pp. 91-108.

Forlin, C. (2004), 'Promoting inclusivity in Western Australian schools', International Journal of Inclusive Education, 8:2, pp. 185-202.

Garofolo, R. (2011), 'Not your parents' marching bands: The history of HONK!, pedagogy and music education', International Journal of Community Music, 4:3, pp. 221-36.

Garrett, S. (2010), 'The role of community music in helping disadvantaged young people in South Wales to confront social exclusion', International Journal of Community Music, 3:3, pp. 371-77.

Goodrich, A. (2013), 'Health musicing in a community orchestra', International Journal of Community Music, 6:1, pp. 45-63.

Hassan, N. (2017), 'Re-voicing: Community choir participation as a medium for identity formation amongst people with learning disabilities', International Journal of Community Music, 10:2, pp. 207-25.

Hess, J. (2018), 'Problematizing “diversity," "inclusion,” and “access” in music education', https://www.youtube.com/watch?v=uvTLWfGOP64\&t=8s. Accessed 20 July 2018.

Higgins, L. (2012), Community Music: In Theory and in Practice, Oxford: Oxford University Press.

Higgins, L. and Willingham, L. (2017), Engaging in Community Music: An Introduction, New York: Routledge. 
Hill, B. (2016), 'Sociocultural work and community music in Germany', International Journal of Community Music, 9:1, pp. 7-21.

Howell, G. (2013), 'Finding my place: Examining concepts of community music as a visiting artist in rural East Timor', International Journal of Community Music, 6:1, pp. 65-78.

Johnson, H. (2012), 'Drumming in the transcultural imagination: Taiko, Japan and community music making in Aotearoa/New Zealand', International Journal of Community Music, 5:1, pp. 11-26.

Kennedy, M. C. (2009), 'The Gettin’ Higher Choir: Exploring culture, teaching and learning in a community chorus', International Journal of Community Music, 2:2, pp. 183-200.

Kruse, N. (2013), "“Without U, it's just kulele”: Expressions of leisure and 'ohana in an intergenerational ukulele club', International Journal of Community Music, 6:2, pp. $153-67$.

Levac, D., Colquhoun, H. and O’Brien, K. (2010), 'Scoping studies: Advancing the methodology', Implementation Science, 5:69, pp. 1-9.

Li, S. and Southcott, J. (2012), 'A place for singing: Active music engagement by older Chinese Australians', International Journal of Community Music, 5:1, pp. 59-78.

Mastnak, W. and Neuwirthová, A. (2017), 'Children with Williams Syndrome make music: A community-based care model in the Czech Republic', International Journal of Community Music, 10:3, pp. 341-56. 
McFerran, K. S. and Rickson, D. (2014), 'Community music therapy in schools:

Realigning with the needs of contemporary students, staff and systems', International Journal of Community Music, 7:1, pp. 75-92.

Merwe, J. van der (2017), "We make a song": Moving beyond active music-making in the Field Band Foundation', International Journal of Community Music, 10:2, pp. 121-38.

Niland, A. (2017), 'Singing and playing together: A community music group in an early intervention setting', International Journal of Community Music, 10:3, pp. 27388.

Oehrle, E. (2010), 'Values infusing UKUSA: A developmental community arts programme in South Africa', International Journal of Community Music, 3:3, pp. $379-86$.

Popkewitz, T. S. (1998), Struggling for the Soul: The Politics of Schooling and the Construction of the Teacher, New York: Teachers College Press. (2012), Cosmopolitanism and the Age of School Reform: Science, Education, and Making Society by Making the Child, New York: Routledge.

Phelan, H. (2008), 'Practice, ritual and community music: Doing as identity', International Journal of Community Music, 1:2, pp. 143-58.

Reimann, R. (2012), 'TraLaLa Blip: Community music for the electronically abled', International Journal of Community Music, 5:1, pp. 79-90.

Rickwood, J. (2014), 'African grace in Central Australia: Community choirs, reconciliation and intercultural performance', International Journal of Community Music, 7:3, pp. 343-63. 
Rønningen, A. (2017), 'The Norwegian municipal music and art schools in the light of community music', International Journal of Community Music, 10:1, pp. 33-43.

Saldaña, J. (2013), The Coding Manual for Qualitative Researchers, London: Sage Publications.

Sattler, G. (2013), 'Playing outside the generational square: The intergenerational impact of adult group music learning activities on the broader community', International Journal of Community Music, 6:3, pp. 311-20.

Slee, R. (2001), “'Inclusion in Practice”: Does practice make perfect?', Educational Review, 53:2, pp.113-23.

Slee, R. and Allan, J. (2001), 'Excluding the included: A reconsideration of inclusive education', International Studies in Sociology of Education, 11:2, pp.173-92.

Smith, C. J. (2013), 'Holding the lotus to the rock: Creating dance community in RedState America', International Journal of Community Music, 6:1, pp. 113-23.

Snake-Beings, E. (2017), 'Community of difference: The liminal spaces of the Bingodisiac Orchestra', International Journal of Community Music, 10:2, pp. $109-20$.

Snell, D. (2014), “"The Black Sheep of the Family”: Bogans, borders and New Zealand society', International Journal of Community Music, 7:2, pp. 273-89.

Snow, M. (2013), 'Community music perspectives: Case studies from the United States', International Journal of Community Music, 6:1, pp. 93-111.

Tichkosky, T. (2011), The Question of Access: Disability, Space, Meaning, Toronto: University of Toronto Press. 
Tomlinson, S. (2017) A Sociology of Special and Inclusive Education: Exploring the Manufacture of Inability, New York: Routledge.

Vaugeois, L. C. (2013), 'Colonization and the institutionalization of hierarchies of the human through music education: studies in the education of feeling', Ph.D. thesis, Toronto: University of Toronto.

Veblen, K. (2008), 'The many ways of community music', International Journal of Community Music, 1:1, pp. 5-21.

Veblen, K. and Olsson, B. (2002), 'Community music: Toward an international overview', in R. Colwell and C. Richardson (eds), The New Handbook of Research on Music Teaching and Learning, New York: Oxford University Press, pp. $730-44$.

Weston, D. and Lenette, C. (2016), 'Performing freedom: The role of music-making in creating a community in asylum seeker detention centres', International Journal of Community Music, 9:2, pp. 121-34.

Yerichuk, D. (2014), “"Socialized music”: Historical formations of community music through social rationales', Action, Criticism and Theory for Music Education, $13: 1$, pp. $124-54$.

(2015), 'Grappling with inclusion: Ethnocultural diversity and socio-musical experiences in Common Thread Community Chorus of Toronto', International Journal of Community Music, 8:3, pp. 217-31. 


\section{Contributor details}

Deanna Yerichuk

Deanna's dovetailed passions of singing and community education underpin her academic and professional work. She earned her $\mathrm{PhD}$ in Music Education at the University of Toronto, investigating historical social and musical inclusion efforts of community music schools in Toronto's settlement houses, which earned her the 2012 SOCAN Foundation/CUMS Award for Writings on Canadian Music. Deanna currently coordinates the Community Music program at Wilfrid Laurier University in Canada. Contact:

Wilfrid Laurier University 75 University Ave W, Waterloo, ON N2L 3C5, Canada

E-mail: dyerichuk@wlu.ca

https://orcid.org/0000-0002-8020-7671

\section{Justis Krar}

Justis is a musician studying in the Bachelor of Music Therapy program at Wilfrid Laurier University in Canada. After completing the Music Industry Arts Program at Fanshawe College in Canada he toured internationally and studied Improvised Theatre in Toronto, Canada and Chicago IL. Justis is focused on how music connects with wellbeing, community and education.

Contact:

E-mail: justiskrar@gmail.com

https://orcid.org/0000-0003-4276-401X 